\title{
Obstructive Sleep Apnea is Associated with an Increased Prevalence of Polycythemia in Patients with Chronic Obstructive Pulmonary Disease
}

\author{
Zhaofu Zeng \\ Yan Song \\ Xin $\mathrm{He}(\mathbb{D}$ \\ Haizhen Yang \\ Fang Yue \\ Mengqing Xiong \\ $\mathrm{Ke} \mathrm{Hu}$ (D)
}

Department of Respiratory and Critical Care Medicine, Renmin Hospital of Wuhan University, Wuhan, People's Republic of China
Correspondence: Ke Hu Department of Respiratory and Critical

Care Medicine, Renmin Hospital of

Wuhan University, Wuhan, 430060,

People's Republic of China

Tel +86 I897 I035988

Email huke-rmhospital@I63.com
Purpose: Chronic obstructive pulmonary disease (COPD) and obstructive sleep apnea (OSA) are associated with polycythemia. However, there still remain unanswered questions about the relationship between overlap syndrome (OVS), where OSA and COPD coexist, and polycythemia. Here, we aimed to establish the prevalence of polycythemia in OVS patients and to explore the impact of OSA on polycythemia.

Patients and Methods: Patients with COPD underwent overnight polysomnography (PSG), pulmonary function tests, echocardiography, and complete blood counts. All patients were ethnic Han Chinese and free of prolonged oral corticosteroid use, hematological system disease, severe systemic disease, and other sleep-disordered breathing. OVS was defined as COPD patients with an apnea-hypopnea index $\geq 15$ events/h, and polycythemia was defined as an $\mathrm{Hb}>165 \mathrm{~g} / \mathrm{L}$ in men and $>160 \mathrm{~g} / \mathrm{L}$ in women.

Results: Eight-hundred and eighty-six patients with COPD were included in the analysis. The prevalence of polycythemia was significantly higher in OVS patients than COPD-alone patients $(6.4 \%$ vs $2.9 \%, p<0.05)$. The prevalence of polycythemia increased with OSA severity $\left(\chi^{2}=7.885, p=0.007\right)$, but not in GOLD grade 3-4 COPD patients $\left(\chi^{2}=0.190, p=\right.$ 0.663). After adjusting for confounders, percentage of total sleep time with $\mathrm{SaO}_{2}<90 \%$ $\left(\mathrm{TS}_{90}\right)$ remained independently associated with an increased odds of polycythemia (OR $1.030,95 \%$ CI 1.015-1.046) and, with an increase in $\mathrm{TS}_{90}$, the hemoglobin increased, especially in GOLD grade $1-2$ patients $(p<0.05)$.

Conclusion: Patients with OVS have a higher prevalence of polycythemia than those with COPD alone, and $\mathrm{TS}_{90}$ is an independent factor for polycythemia, especially in GOLD1-2 COPD patients. Keywords: chronic obstructive pulmonary disease, obstructive sleep apnea, overlap syndrome, polycythemia

\section{Introduction}

Chronic obstructive pulmonary disease (COPD) is a common and chronic respiratory disease that affects over 380 million people worldwide. COPD has a prevalence of $\sim 10 \%$, and its healthcare burden is expected to rise over the next forty years due to increasing numbers of deaths attributable to the disease. ${ }^{1}$ COPD is characterized by progressive and persistent airflow limitation resulting in chronic sustained hypoxia and acquired polycythemia, and the latter is closely associated with an increased risk of stroke, venous thromboembolism (VTE), pulmonary hypertension $(\mathrm{PH})$, and mortality. ${ }^{2,3}$ Furthermore, polycythemia remains present in $2-10 \%$ of COPD patients even after long-term oxygen therapy. ${ }^{4-6}$ 
Obstructive sleep apnea (OSA) is characterized by recurrent episodes of partial or complete collapse of the upper airway during sleep, and it can lead to chronic intermittent hypoxia related to red blood cell (RBC) proliferation. ${ }^{7,8}$ OSA severity is significantly associated with hemoglobin $(\mathrm{Hb})$ and $\mathrm{RBC}$ counts, ${ }^{7}$ and the prevalence of polycythemia in OSA patients is reported to be between $1.6 \%$ and $10 \% .{ }^{9,10}$ Furthermore, RBC count and hemoglobin significantly decreased in OSA patients after continuous positive airway pressure (CPAP) therapy. ${ }^{11}$

Overlap syndrome (OVS) refers to the occurrence of COPD and OSA in the same individual. The pathophysiological changes of COPD and OSA are often superimposed or synergistic in OVS patients, the most significant of which is chronic hypoxia. However, there is considerable complexity to the underlying biology of sustained versus intermittent hypoxia in stimulating erythroid hyperplasia, ${ }^{12,13}$ although it is widely recognized that OVS patients may be particularly vulnerable to oxyhemoglobin desaturation during sleep. ${ }^{14}$

We previously showed that OVS patients have higher RBC counts than COPD patients; ${ }^{15}$ however, whether OSA increases the prevalence of polycythemia in COPD patients remains unillustrated. It is also important to firmly establish whether polycythemia is associated with other complications in COPD patients to understand the possible adverse effects of polycythemia on prognosis. Therefore, in this cross-sectional study, we assessed the prevalence of polycythemia in OVS patients to explore the role and mechanism of OSA in the disease and to understand the relationship between polycythemia and other comorbidities.

\section{Methods}

\section{Subjects}

From December 2016 to August 2020, 1048 participants diagnosed with COPD were enrolled in the study and underwent polysomnography (PSG). Patients in the primary cohort were recruited from four Chinese tertiary hospitals under the auspices of a national COPD Research and Development Program (Clinical Trials ID: NCT 03182309). Eight hundred and eighty-six patients met the following inclusion criteria and were included in the study (Figure 1): (1) age over 40 years; (2) postbronchodilator forced expiratory volume in 1 second $\left(\mathrm{FEV}_{1}\right)$ /forced vital capacity $(\mathrm{FVC})<0.7$ without any exacerbations in the preceding three months; and (3) willingness to participate in the study and provide written informed consent. The following exclusion criteria were applied: (1) non-Han ethnicity; (2) long-term history of high-altitude exposure; (3) prolonged use of high-dose glucocorticoids or other drugs that affect blood cell production; (4) severe systemic disease (eg, severe infection, malignancy, severe liver and renal dysfunction); (5) hematological disease (eg, leukemia, lymphoma, anemia, polycythemia vera); and (6) known sleep-disordered breathing other than OSA. The study was approved by the Scientific Research and Technology Ethics Committee of Renmin Hospital of Wuhan University and conducted in accordance with the Declaration of Helsinki.

\section{Clinical Assessment and Anthropometric Measurements}

Current or former smoking and drinking habits and treatments for COPD were recorded, as were a past medical history of hypertension, stroke, coronary heart disease (CHD), thyroid dysfunction, diabetes, gastritis, and venous thromboembolism (VTE; including pulmonary embolism or deep vein thrombosis). Body mass index (BMI) was obtained by dividing body weight by height squared.

\section{Pulmonary Function Tests}

The FVC and the $\mathrm{FEV}_{1}$ were measured with a spirometer (Jaeger MasterScreen Body, Germany). The $\mathrm{FEV}_{1} / \mathrm{FVC}$ and predicted percentage of $\mathrm{FEV}_{1}\left(\mathrm{FEV}_{1} \%\right)$ and $\mathrm{FVC}$ (FVC\%) were calculated. According to Global Initiative for Chronic Obstructive Lung Disease (GOLD) guidelines, patients were divided into those with GOLD grade 1-2 $\left(\mathrm{FEV}_{1} \% \geq 50 \%\right)$ and GOLD grade $3-4 \mathrm{COPD}\left(\mathrm{FEV}_{1} \%<\right.$ $50 \%){ }^{16}$

\section{PSG Monitoring}

All patients underwent overnight PSG (SOMNOscreen Plus Tele PSG, SOMNOmedics GmbH, Randersacker, Germany) in the hospital's sleep-monitoring room. The parameters investigated included airflow, electroencephalography, electrooculography, electrocardiography, electromyography, thoracic and abdominal respiratory effort, snoring, body position, and pulse oxygen saturation $\left(\mathrm{SaO}_{2}\right)$. The apnea-hypopnea index (AHI), average $\mathrm{SaO}_{2}$ (mean $\mathrm{SaO}_{2}$ ), lowest $\mathrm{SaO}_{2}\left(\right.$ min $\mathrm{SaO}_{2}$ ), oxygen desaturation index (ODI), and percentage of total sleep time spent with $\mathrm{SaO}_{2}<90 \%\left(\mathrm{TS}_{90}\right)$ were recorded by PSG. Standard PSG was performed by trained sleep technicians and the 


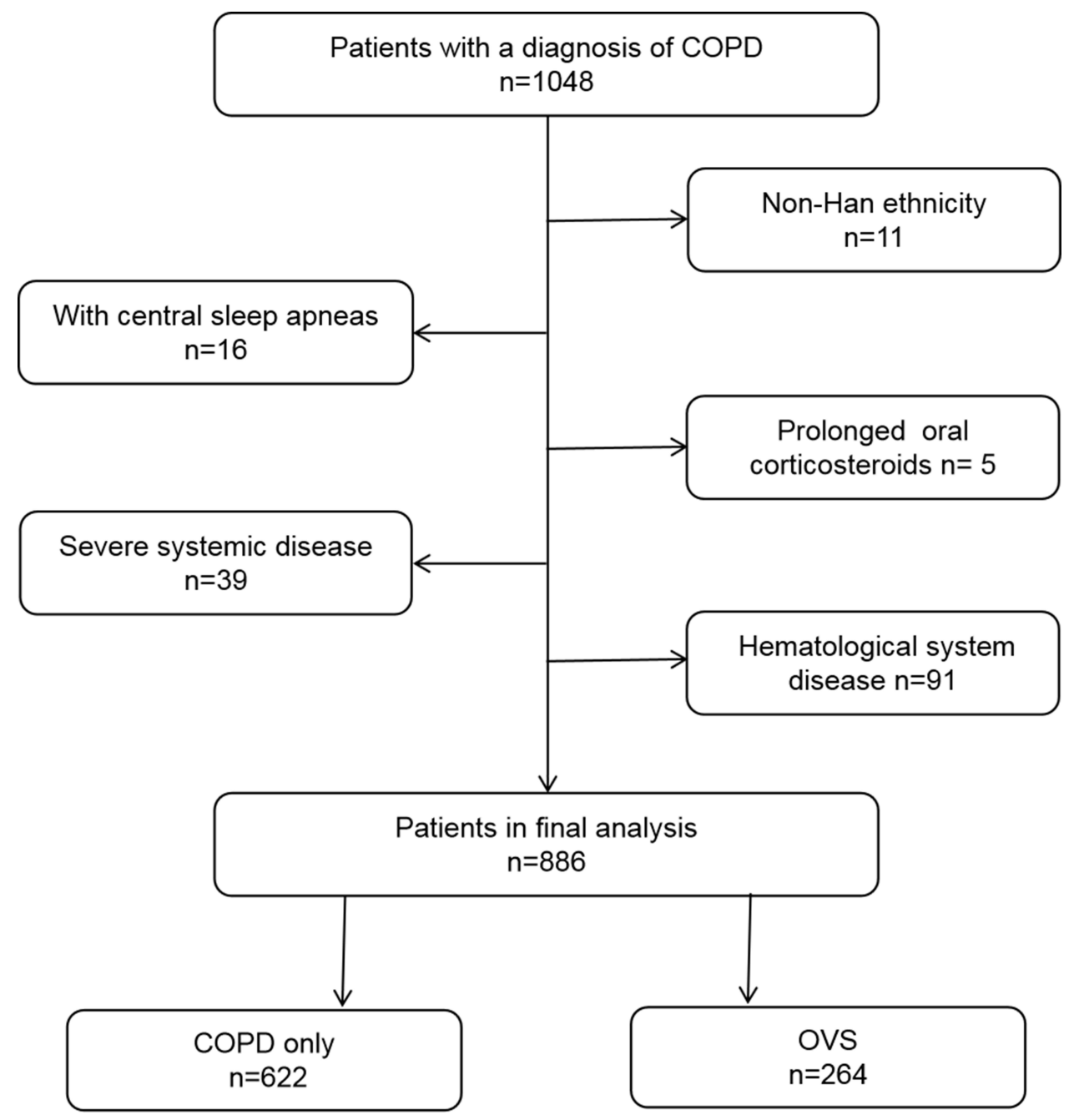

Figure I Study flow diagram.

Abbreviations: OVS, overlap syndrome; COPD, chronic obstructive pulmonary disease.

recordings were analyzed according to the criteria outlined in the 2016 American Academy of Sleep Medicine (AASM) Manual v.2.3. ${ }^{17}$ All patients were diagnosed with OVS if they had an AHI $\geq 15$ events/h, and OVS was further dichotomized into those with an AHI of 15 to $<30$ events/h and those with an AHI $\geq 30$ events $/ \mathrm{h}$. All OSA patients are newly diagnosed patients and have not been treated with CPAP.

\section{Echocardiography}

All subjects received standard transthoracic Dopplerechocardiography (LOGIQE9, General Electric Company, Boston, MA, USA) by an experienced ultrasound examiner, and the results were confirmed by at least two echocardiography specialists. PH was diagnosed by echocardiography. ${ }^{18}$

\section{Laboratory Measurements}

Fasting blood samples were taken the next morning immediately after PSG. Complete blood cell counts were assessed with an automated count analyzer. The following hematological indices were obtained: white blood cell (WBC) count, $\mathrm{RBC}$ count, $\mathrm{Hb}$, and platelets (PLT). Polycythemia was defined as an $\mathrm{Hb}>165 \mathrm{~g} / \mathrm{L}$ in men and $>160 \mathrm{~g} / \mathrm{L}$ in women. ${ }^{19}$

\section{Statistical Analysis}

SPSS v25.0 (IBM Statistics, Armonk, NY) statistical software was used for data analysis. Normally distributed data were expressed with means \pm standard deviations (SD) and compared using one-way analysis of variance (ANOVA) or $t$-tests, while non-normally distributed data were expressed as medians and interquartile ranges (IQR) and compared using the Kruskal-Wallis test or $U$-test. Count 
data were presented as rates or composition ratios and were tested using the chi-squared test or Fisher's exact test. Analysis of covariance (ANCOVA) was used to compare linear regression slopes. After univariate analysis, variance inflation factor (VIF) was used to evaluate the collinearity of variables, and binary multivariate logistic regression was applied to further analyze variables with a VIF $<3$. A $p$-value $<0.05$ was considered significant.

\section{Results}

\section{Baseline Data and Clinical Characteristics}

Eighteen patients had polycythemia among 622 (2.9\%) patients with COPD alone, and 17 patients had polycythemia among $264(6.4 \%)$ patients with OVS $(p<0.05$; Figure 2). Subgroup analyses were conducted according to OSA severity, and the baseline characteristics of the subgroups are shown in Table 1 . There were no significant differences in age, tobacco use, and $\mathrm{FVC} \%$ between groups (all $p>0.05$ ), but there were significant differences in gender, BMI, neck circumference, alcohol use, FVC, $\mathrm{FEV}_{1}, \mathrm{FEV}_{1} \%$, and $\mathrm{FEV}_{1} / \mathrm{FVC}$ between groups (all $p<0.05)$. There were no significant differences in the prevalence of PH, VTE, CHD, hypertension, stroke, thyroid dysfunction, diabetes, or gastritis between groups (all $p>0.05$ ), neither were there statistical differences between groups with respect to COPD treatments (all $p>0.05$ ).

\section{The Relationship Between the Severity of OSA and Prevalence of Polycythemia}

$\mathrm{Hb}$ and $\mathrm{RBC}$ counts significantly increased with the severity of OSA $(p<0.05)$ in all patients with GOLD1-2 COPD (Figure 3).

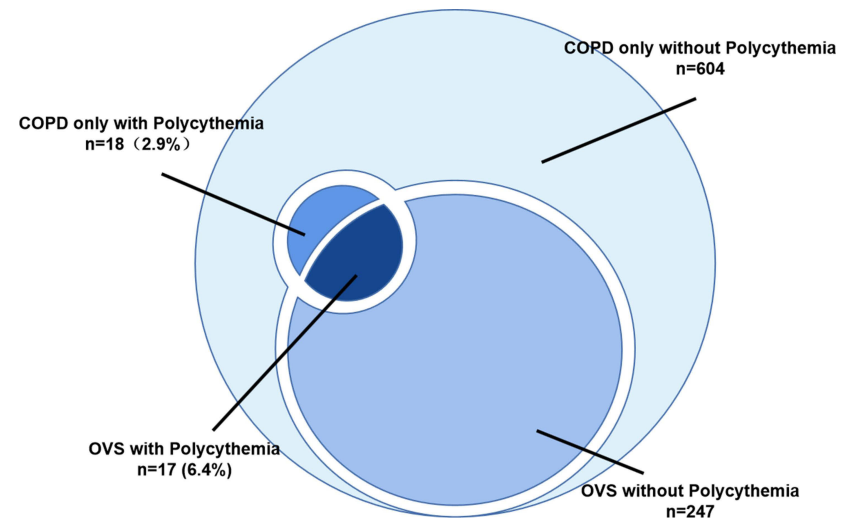

Figure 2 Venn diagram illustrating the prevalence of polycythemia in OVS patients and COPD-only patients.Four colors represented different groups of patients and there were 18 patients with polycythemia among COPD-alone patients (18/18 $+604)$ and 17 patients with polycythemia among OVS patients $(17 / 17+247)$.

Abbreviations: OVS, overlap syndrome; COPD, chronic obstructive pulmonary disease.
Consistent with this, as OSA severity increased, the prevalence of polycythemia gradually increased $\left(\chi^{2}=7.885, p=0.007\right)$. This increasing trend was observed for GOLD1-2 $\left(\chi^{2}=10.796\right.$, $p=0.001)$ but not GOLD3-4 COPD patients $\left(\chi^{2}=0.190\right.$, $p=0.663$ ) (Figure 4). Interestingly, there was no significant increase in the prevalence of polycythemia with an increase in the severity of airflow limitation.

\section{Independent Factors Associated with Polycythemia}

Patients with polycythemia were younger, heavier, and had a larger neck circumference (all $p<0.01$ ). The $\mathrm{TS}_{90}$ and ODI of patients with polycythemia were higher and the $\min \mathrm{SaO}_{2}$ and mean $\mathrm{SaO}_{2}$ were lower $(p<0.05)$ in patients with polycythemia (Table 2). Increased $\mathrm{TS}_{90}$ was associated with an increased odds of polycythemia (OR 1.029, 95\% CI 1.019-1.039) in binary logistic regression analysis. When adjusted for gender, age, BMI, neck circumference, OSA, $\min \mathrm{SaO}_{2}$, mean $\mathrm{SaO}_{2}$, tobacco use, alcohol use, $\mathrm{FEV}_{1} \%$, and $\mathrm{FEV}_{1} / \mathrm{FVC}$, increased $\mathrm{TS}_{90}$ still remained associated with an increased odds of polycythemia (OR 1.029, 95\% CI 1.014-1.044) (Table 3). After adjusting for the above factors, $\mathrm{TS}_{90}$ was still associated with polycythemia in both GOLD1-2 and GOLD3-4 COPD patients (OR 1.031, 95\% CI 1.007-1.056; OR 1.028, 95\% CI 1.006-1.050, respectively) (Table 4). Figure 5 shows that with an increase in $\mathrm{TS}_{90}, \mathrm{Hb}$ levels and $\mathrm{RBC}$ counts gradually increased, especially in GOLD1-2 COPD patients $(p<0.05)$.

\section{Discussion}

The reported incidence of polycythemia varies with the use of different diagnostic criteria. The prevalence of polycythemia in COPD patients is reported to range from $5.9 \%$ to $10.2 \%$ when defined as an $\mathrm{Hb} \geq 170 \mathrm{~g} / \mathrm{L}$ in males and $\geq 150$ $\mathrm{g} / \mathrm{L}$ in females, but Frank et al reported that only $2 \%$ of COPD patients had polycythemia. ${ }^{4}$ Zhang et al found that $6.6 \%$ of COPD patients met the diagnostic criteria for polycythemia with a cutoff of $\mathrm{Hb}>165 \mathrm{~g} / \mathrm{L}$ in males and $>160 \mathrm{~g} / \mathrm{L}$ in females and suggested that race and altitude have an impact on the prevalence of polycythemia. ${ }^{20}$ In our study, the prevalence of polycythemia was only $3.9 \%$, which might be because all our patients lived at high altitudes and ethnic groups other than Han were excluded.

We found that the prevalence of polycythemia in OVS patients was $6.4 \%$ and that the severity of disease was positively associated with the prevalence of polycythemia. In a nationwide study in the USA, Pathak et al screened $77,518,944$ patients through a medical system and, after 
Table I Baseline Characteristics, Comorbidities, Sleep and Laboratory Data of the COPD Only and the OVS Groups

\begin{tabular}{|c|c|c|c|c|}
\hline \multirow[t]{2}{*}{ Parameters } & \multirow[t]{2}{*}{ COPD Only Group } & \multicolumn{2}{|c|}{ OVS Group } & \multirow[t]{2}{*}{$p$} \\
\hline & & $\mathbf{I} 5 \leq \mathrm{AHI}<\mathbf{3 0}$ & $\mathrm{AHI} \geq \mathbf{3 0}$ & \\
\hline Number of patients, $n$ (\%) & $622(70.2 \%)$ & 157 (I7.7\%) & $107(12.1 \%)$ & - \\
\hline Male, n (\%) & $530(85.2 \%)$ & 142 (90.4\%) & $103(96.3 \%)$ & 0.003 \\
\hline Age (year) & $68.1 \pm 8.5$ & $67.8 \pm 9.6$ & $66.3 \pm 10.2$ & 0.140 \\
\hline BMI $\left(\mathrm{kg} / \mathrm{m}^{2}\right)$ & $23.4 \pm 4.0$ & $24.3 \pm 4.1$ & $26.2 \pm 5.0$ & $<0.001$ \\
\hline Neck circumference $(\mathrm{cm})$ & $38.3 \pm 3.1$ & $38.8 \pm 3.0$ & $40.6 \pm 3.9$ & $<0.001$ \\
\hline Tobacco use, $\mathrm{n}(\%)$ & $517(83.1 \%)$ & $|3|(83.4 \%)$ & 91 (85.0\%) & 0.885 \\
\hline Alcohol use, n (\%) & $250(40.2 \%)$ & $80(51.0 \%)$ & $56(52.3 \%)$ & 0.008 \\
\hline $\mathrm{FVC}(\mathrm{L})$ & $2.7 \pm 0.9$ & $2.9 \pm 1.0$ & $3.0 \pm 1.0$ & 0.001 \\
\hline FVC\% & $81.5 \pm 23.0$ & $85.7 \pm 23.5$ & $84.1 \pm 23.0$ & 0.095 \\
\hline $\mathrm{FEV}_{\mathrm{I}}(\mathrm{L})$ & $1.3 \pm 0.6$ & $1.6 \pm 0.7$ & $1.8 \pm 0.3$ & $<0.001$ \\
\hline $\mathrm{FEV}, \%$ & $51.3 \pm 20.9$ & $57.6 \pm 21.5$ & $61.7 \pm 21.5$ & $<0.001$ \\
\hline $\mathrm{FEV}_{\mathrm{I}} / \mathrm{FVC}(\%)$ & $49.2 \pm 12.4$ & $53.3 \pm 11.5$ & $57.3 \pm 11.3$ & $<0.001$ \\
\hline $\mathrm{AHI}$ (events/h) & $4.8(1.7,8.9)$ & $20.7(18.0,24.7)$ & $41.6(34.3,55.7)$ & $<0.001$ \\
\hline $\mathrm{TS}_{90}(\%)$ & I.I $(0.1,7.0)$ & $5.2(1.4,15.1)$ & I2.9 (5.I,32.8) & $<0.001$ \\
\hline $\min \mathrm{SaO}_{2}(\%)$ & $85.0(81.0,89.0)$ & $81.0(74.7,85.0)$ & $77.0(68.0,84.0)$ & $<0.001$ \\
\hline mean $\mathrm{SaO}_{2}(\%)$ & $94.0(92.0,95.0)$ & $93.0(92.0,94.4)$ & $93.0(91.0,94.0)$ & 0.001 \\
\hline ODI (events/h) & $4.0(1.7,7.7)$ & $17.4(8.4,22.2)$ & $32.2(11.3,44.9)$ & $<0.001$ \\
\hline $\mathrm{Hb}(\mathrm{g} / \mathrm{L})$ & $14 \mid .5 \pm 13.3$ & $143.6 \pm 13.2$ & $145.4 \pm 17 . \mid$ & 0.011 \\
\hline RBC count $\left(\times 10^{12} / \mathrm{L}\right)$ & $4.61 \pm 0.5$ & $4.64 \pm 0.5$ & $4.76 \pm 0.6$ & 0.012 \\
\hline WBC count $\left(\times 10^{9} / \mathrm{L}\right)$ & $7.37 \pm 2.9$ & $6.85 \pm 2.5$ & $7.80 \pm 2.8$ & 0.024 \\
\hline PLT count $\left(\times 10^{9} / \mathrm{L}\right)$ & $215.5 \pm 64.5$ & $212.8 \pm 74.8$ & $219.6 \pm 58.9$ & 0.709 \\
\hline Polycythemia, n (\%) & 18 (2.9\%) & $8(5.1 \%)$ & $9(8.4 \%)$ & 0.018 \\
\hline GOLD I-2 $(n=454)$ & 7 (2.4\%) & 7 (7.4\%) & 8 (1 1.0\%) & 0.005 \\
\hline GOLD 3-4 $(n=432)$ & II (3.3\%) & $\mathrm{I}(\mathrm{l} .6 \%)$ & I (2.9\%) & 0.884 \\
\hline $\mathrm{PH}, \mathrm{n}(\%)$ & $32(5.1 \%)$ & $9(5.7 \%)$ & $4(3.7 \%)$ & 0.762 \\
\hline VTE, n (\%) & $5(0.8 \%)$ & I (0.6\%) & I (0.9\%) & 0.962 \\
\hline CHD, n (\%) & $126(20.3 \%)$ & $24(15.3 \%)$ & $19(17.8 \%)$ & 0.342 \\
\hline Hypertension, n (\%) & $254(40.8 \%)$ & 7I (45.2\%) & $55(51.4 \%)$ & 0.101 \\
\hline Stroke, n (\%) & $39(6.3 \%)$ & $10(6.4 \%)$ & II (I0.3\%) & 0.305 \\
\hline Thyroid dysfunction, n (\%) & $8(1.3 \%)$ & $6(3.8 \%)$ & $3(2.8 \%)$ & 0.055 \\
\hline Diabetes, n (\%) & $68(10.9 \%)$ & $16(10.2 \%)$ & II (10.3\%) & 0.956 \\
\hline Gastritis, n (\%) & 28 (4.5\%) & 7 (4.5\%) & $3(2.8 \%)$ & 0.838 \\
\hline NIV, n (\%) & $20(3.2 \%)$ & $\mathrm{I}(0.6 \%)$ & $6(5.6 \%)$ & 0.055 \\
\hline LAMA, n (\%) & $52(8.4 \%)$ & $15(9.6 \%)$ & $9(8.4 \%)$ & 0.913 \\
\hline LABA+ICS, n (\%) & I 42 (22.8\%) & 41 (26.1\%) & 21 (19.6\%) & 0.464 \\
\hline LAMA+LABA+ICS, n (\%) & $61(9.8 \%)$ & $12(7.6 \%)$ & $5(4.7 \%)$ & 0.193 \\
\hline
\end{tabular}

Abbreviations: $\mathrm{BMI}$, body mass index; $\mathrm{FVC}$, forced vital capacity; $\mathrm{FEV}_{1}$, forced expiratory volume in the first second; $\mathrm{AH}$, apnea hypopnea index; $\mathrm{TS}_{90}$, percentage of time spent with an $\mathrm{SaO}_{2}$ below $90 \%$; mean $\mathrm{SaO}_{2}$, average pulse oxygen saturation; min $\mathrm{SaO}_{2}$, lowest pulse oxygen saturation; ODI, oxygen desaturation index; $\mathrm{Hb}$, hemoglobin; RBC, red blood cell; WBC, white blood cell; PLT, platelets; PH, pulmonary hypertension; VTE, venous thromboembolism; CHD, coronary heart disease; NIV, non-invasive ventilation; LAMA, long-acting anticholinergics; LABA, long-acting beta 2-agonist; ICS, inhaled corticosteroids.

excluding other possible causes of secondary erythrocytosis, diagnosed 2,765,267 OSA patients, of whom 13,016 had polycythemia. Furthermore, the presence of OSA was associated with an increased odds of polycythemia (OR 5.9, 95\% CI 5.65-6.17). ${ }^{21}$ In another study, OSA was an independent predictor for polycythemia in patients receiving androgen supplementation. ${ }^{22}$ Moreover, in the report by $\mathrm{Li}$ et al. ${ }^{10}$ OSA severity was related to the prevalence of polycythemia and mean $\mathrm{SaO}_{2}$ was an independent predictor of polycythemia. We found that the presence of polycythemia was related to age, BMI, neck circumference, severe OSA, min $\mathrm{SaO}_{2}$, mean $\mathrm{SaO}_{2}, \mathrm{ODI}$, and $\mathrm{TS}_{90}$ in binary logistic regression analysis, and multivariate analysis showed that age and $\mathrm{TS}_{90}$ were independent predictors after adjusting for other confounders. On this basis, we further compared the diagnostic value of min $\mathrm{SaO}_{2}$, mean $\mathrm{SaO}_{2}$, and $\mathrm{TS}_{90}$ for 


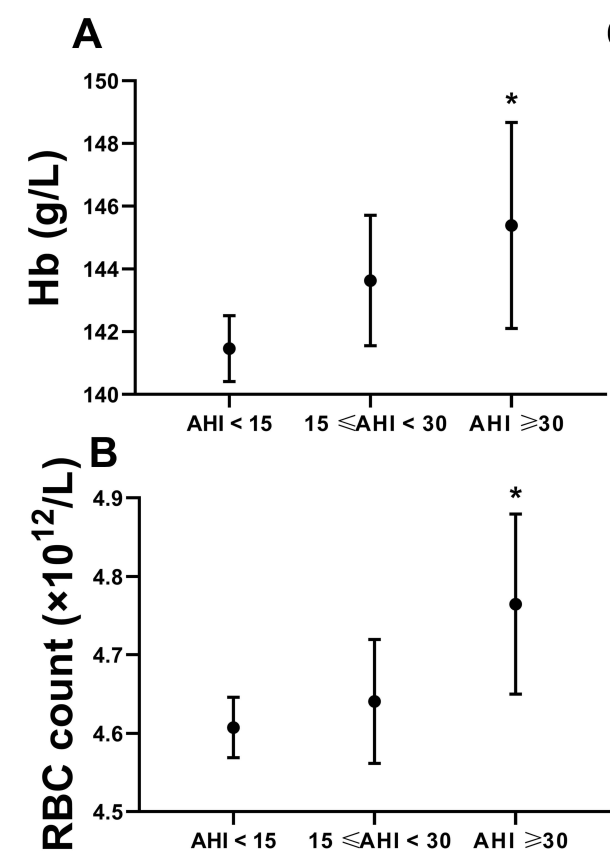

All patients
C

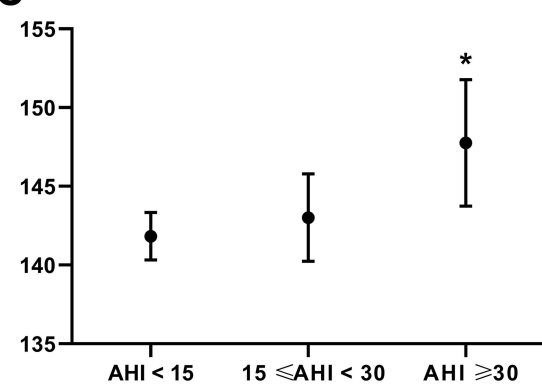

D

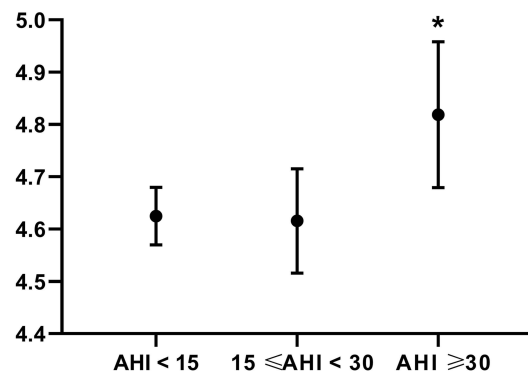

GOLD1-2

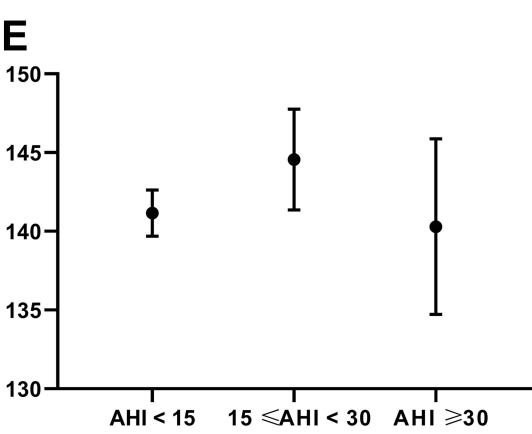

$\mathbf{F}$

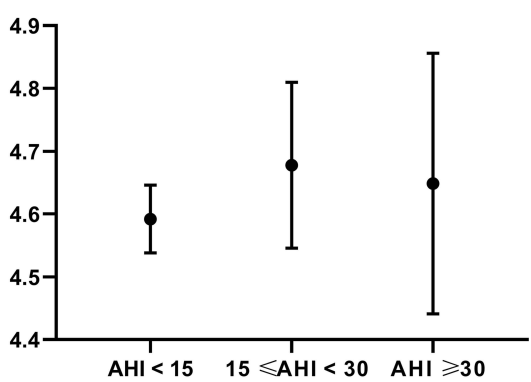

GOLD3-4

Figure 3 The effect of severity of OSA on RBC and $\mathrm{Hb}$ according to GOLD grade of COPD patients. (A and B) The effect of severity of OSA on RBC and Hb in all patients with COPD. (C and D) The effect of severity of OSA on RBC and Hb in GOLD I-2 patients. (E and F) The effect of severity of OSA on RBC and Hb in GOLD 3-4 patients. $* p<0.05$ indicates a significant difference between groups.

Abbreviations: RBC, red blood cell; Hb, hemoglobin.

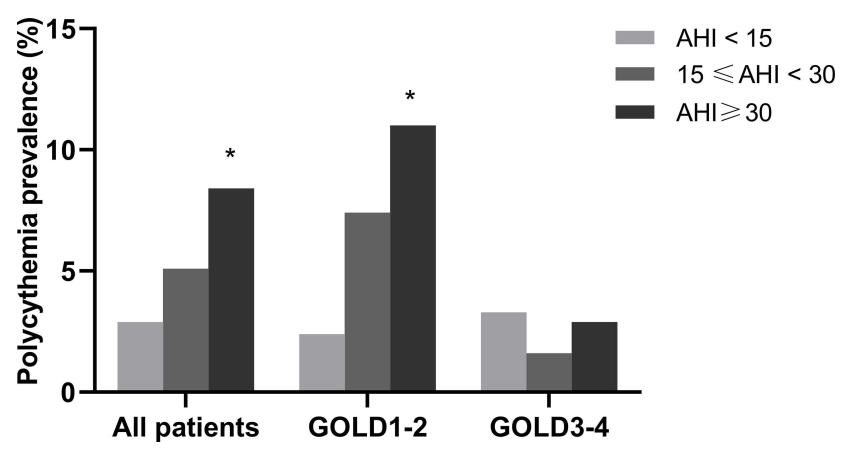

Figure 4 The prevalence of polycythemia among patients with stratified OSA severity. ${ }^{*} p<0.05$ indicates that the prevalence of polycythemia significantly increased with OSA severity by the linear-by-linear association test.

polycythemia (Supplementary Figure 1). It is currently accepted that intermittent hypoxia can inhibit the degradation of hypoxia-inducible factor (HIF), thereby promoting the secretion of erythropoietin (EPO) and leading to $\mathrm{RBC}$ proliferation. $^{23,24}$ Furthermore, hypoxia stimulation has been shown to increase atrial natriuretic peptide, which can lead to relative polycythemia. ${ }^{25}$

Unexpectedly, the prevalence of polycythemia did not differ between OVS patients and COPD-only patients with GOLD3-4 disease. We believe that this might be for several reasons: first, the effects of hypoxic stimulation and inflammation on the hematopoietic system were balanced, since hypoxic stimulation is thought to induce quantitative changes while inflammation results in qualitative changes ${ }^{26,27}$ ie, more severe inflammation results in obvious EPO resistance or hematopoietic dysfunction in severe COPD. ${ }^{5}$ Therefore, the effect of hypoxia on RBC proliferation was significantly reduced. Second, although COPD and OSA have similar pathophysiology such as chronic hypoxia, chronic sustained hypoxia and chronic intermittent hypoxia have different effects on RBC production. To support this, Song et $\mathrm{al}^{24}$ observed the destruction of new RBCs after reoxygenation in patients with chronic sustained hypoxia (neocytolysis), but this phenomenon was rare in OSA patients. Therefore, since patients with severe COPD may experience more serious neocytolysis, the increase in RBC counts due to OSA was not significant. Ryan et al ${ }^{13}$ also postulated that the impact of chronic hypoxia on the hematopoietic system involves two main pathways: adaptive and inflammatory. The adaptive pathway places HIF at the center and stimulates erythropoiesis, while the inflammatory pathway is mediated by NF- $\mathrm{BB}$ and causes inflammation. This difference in hypoxia pathway 
Table 2 Demographic and Clinical Characteristics of Patients with or without Polycythemia

\begin{tabular}{|c|c|c|c|}
\hline Parameters & $\begin{array}{l}\text { Without Polycythemia } \\
\qquad(n=85 I)\end{array}$ & $\begin{array}{l}\text { With Polycythemia } \\
\qquad(n=35)\end{array}$ & $p$ \\
\hline Male, n (\%) & $74 \mid(87.1 \%)$ & 34 (97.1\%) & 0.078 \\
\hline Age (year) & $68.1 \pm 8.8$ & $61.7 \pm 9.2$ & $<0.001$ \\
\hline BMI $\left(\mathrm{kg} / \mathrm{m}^{2}\right)$ & $23.8 \pm 4.2$ & $26.2 \pm 4.8$ & 0.001 \\
\hline Neck circumference $(\mathrm{cm})$ & $38.6 \pm 3.2$ & $40.4 \pm 3.6$ & 0.002 \\
\hline Tobacco use, n (\%) & $710(83.4 \%)$ & $29(82.9 \%)$ & 0.929 \\
\hline Alcohol, n (\%) & $366(43 \%)$ & $20(57.1 \%)$ & 0.098 \\
\hline $\mathrm{FVC}(\mathrm{L})$ & $2.8 \pm 0.9$ & $3.1 \pm 0.8$ & 0.034 \\
\hline FVC\% & $82.5 \pm 23.3$ & $82.8 \pm 18.1$ & 0.940 \\
\hline $\mathrm{FEV}_{\mathrm{I}}(\mathrm{L})$ & $1.4 \pm 0.7$ & $1.6 \pm 0.7$ & 0.064 \\
\hline $\mathrm{FEV}_{1} \%$ & $53.6 \pm 21.4$ & $55.0 \pm 21.3$ & 0.716 \\
\hline FEV,/FVC(\%) & $51.0 \pm 12.4$ & $51.8 \pm 14.0$ & 0.662 \\
\hline $\mathrm{AHI}$ (events/h) & $7.8(3.0,17.7)$ & $11.9(2.4,34.7)$ & 0.150 \\
\hline $\mathrm{TS}_{90}(\%)$ & $2.3(0.2,11.2)$ & $12.3(1.0,71.8)$ & $<0.001$ \\
\hline $\min \mathrm{SaO}_{2}(\%)$ & $84.0(79.0,88.0)$ & $78.0(69.0,84.0)$ & $<0.001$ \\
\hline mean $\mathrm{SaO}_{2}(\%)$ & $93.8(92.0,95.0)$ & $91.4(86.0,93.0)$ & $<0.001$ \\
\hline ODI (events/h) & $5.7(2.4,13.1)$ & $12.8(3.4,37.0)$ & 0.012 \\
\hline $\mathrm{Hb}(g / L)$ & $140.9 \pm 12.0$ & $176.5 \pm 13.1$ & $<0.001$ \\
\hline RBC count $\left(\times 10^{12} / L\right)$ & $4.59 \pm 0.5$ & $5.74 \pm 0.5$ & $<0.001$ \\
\hline WBC count $\left(\times 10^{9} / \mathrm{L}\right)$ & $7.3 \pm 2.9$ & $7.3 \pm 2.4$ & 0.985 \\
\hline PLT count $\left(\times 10^{9} / \mathrm{L}\right)$ & $216.6 \pm 65.7$ & $188.9 \pm 61.0$ & 0.014 \\
\hline $\mathrm{PH}, \mathrm{n}(\%)$ & $40(4.7 \%)$ & $5(14.3 \%)$ & 0.028 \\
\hline VTE, n (\%) & $7(0.8 \%)$ & 0 & 0.753 \\
\hline CHD, n (\%) & $162(19 \%)$ & $7(20 \%)$ & 0.887 \\
\hline Hypertension, n (\%) & $362(42.5 \%)$ & $18(51.4 \%)$ & 0.298 \\
\hline Stroke, n (\%) & $59(6.9 \%)$ & I (2.9\%) & 0.506 \\
\hline Thyroid dysfunction, n (\%) & $17(2.0 \%)$ & 0 & 0.643 \\
\hline Diabetes, n (\%) & $92(10.8 \%)$ & $3(8.6 \%)$ & 0.790 \\
\hline Gastritis, n (\%) & 38 (4.5\%) & 0 & 0.267 \\
\hline NIV, n (\%) & $25(2.9 \%)$ & $2(5.7 \%)$ & 0.621 \\
\hline LAMA, n (\%) & $73(8.6 \%)$ & $3(8.6 \%)$ & 1.000 \\
\hline LABA+ICS, n (\%) & $198(23.3 \%)$ & $6(17.1 \%)$ & 0.427 \\
\hline LAMA+LABA+ICS, n (\%) & $75(8.8 \%)$ & $3(8.6 \%)$ & 1.000 \\
\hline
\end{tabular}

Abbreviations: BMI, body mass index; FVC, forced vital capacity; $\mathrm{FEV}_{1}$, forced expiratory volume in the first second; AHI, apnea hypopnea index; $\mathrm{TS}_{90}$, percentage of time spent with an $\mathrm{SaO}_{2}$ below $90 \%$; mean $\mathrm{SaO}_{2}$, average pulse oxygen saturation; min $\mathrm{SaO}_{2}$, lowest pulse oxygen saturation; ODI, oxygen desaturation index; $\mathrm{Hb}$, hemoglobin; RBC, red blood cell; WBC, white blood cell; PLT, platelets; PH, pulmonary hypertension; VTE, venous thromboembolism; CHD, coronary heart disease; NIV, non-invasive ventilation; LAMA, long-acting anticholinergics; LABA, long-acting beta 2-agonist; ICS, inhaled corticosteroids.

activation leads to different effects on erythropoiesis. Finally, severe COPD patients are often older, more malnourished, and receive long-term oxygen therapy, which might also influence the hematopoietic process.

After adjusting for gender, age, BMI and other factors, we found that polycythemia was associated with pulmonary hypertension (Supplementary Table 1), which is consistent with previous studies. ${ }^{14,28}$ Increased circulating RBCs increase pulmonary vascular resistance and pulmonary arterial pressure through an increase in blood viscosity. Unfortunately, poor vessel compliance in COPD patients may exacerbate this change. ${ }^{29}$ Interestingly, there were only six cases of VTE in our cohort, of whom none had polycythemia. A case-control study revealed no difference in the number of VTE events in COPD patients with and without secondary polycythemia, although there was a significant difference in $\mathrm{PH}^{30}$ In this regard, we speculate that polycythemia in COPD patients may have a greater impact on the pulmonary arteries. We also compared the prevalence of other comorbidities including hypertension, diabetes, and stroke between OVS and COPD only groups. Interestingly, although there was no statistically significant difference between the two groups for hypertension, the OVS group had a trend towards more frequent hypertension $(40.8 \% \mathrm{vs}$ 
Table 3 Results of Logistic Regression in Analyzing the Effect of OSA Severity and Other Parameters on Polycythemia on All of Patients with COPD

\begin{tabular}{|c|c|c|c|c|}
\hline \multirow[t]{2}{*}{ Parameters } & \multicolumn{2}{|c|}{$\begin{array}{c}\text { Univariate } \\
\text { Regression } \\
\text { Analysis }\end{array}$} & \multicolumn{2}{|c|}{$\begin{array}{c}\text { Multiple } \\
\text { Regression } \\
\text { Analysis }\end{array}$} \\
\hline & OR & $p$ & OR & $p$ \\
\hline Male & 5.047 & 0.112 & 5.896 & 0.145 \\
\hline Age (year) & 0.925 & $<0.001$ & 0.929 & 0.001 \\
\hline BMI $\left(\mathrm{kg} / \mathrm{m}^{2}\right)$ & 1.115 & 0.002 & 1.090 & 0.168 \\
\hline Neck circumference $(\mathrm{cm})$ & 1.169 & 0.002 & 1.004 & 0.957 \\
\hline \multicolumn{5}{|l|}{$\mathrm{AHI}$ (events/h) } \\
\hline $\mathrm{AHI}<\mathrm{I} 5$ & 1 & - & I & - \\
\hline $\mathrm{I} 5 \leq \mathrm{AHI}<30$ & 1.082 & 0.176 & 1.363 & 0.546 \\
\hline $\mathrm{AHI} \geq 30$ & 3.082 & 0.008 & 1.168 & 0.829 \\
\hline $\mathrm{TS}_{90}(\%)$ & 1.029 & $<0.001$ & 1.029 & $<0.001$ \\
\hline $\min \mathrm{SaO}_{2}(\%)$ & 0.959 & $<0.001$ & 0.985 & 0.392 \\
\hline mean $\mathrm{SaO}_{2}(\%)$ & 0.933 & 0.003 & 1.014 & 0.756 \\
\hline ODI (events/h) & 1.031 & $<0.001$ & 0.995 & $0.74 I$ \\
\hline Tobacco use & 0.960 & 0.929 & 0.501 & 0.216 \\
\hline Alcohol use & 1.767 & 0.102 & 1.798 & 0.143 \\
\hline $\mathrm{FEV}_{1} \%$ & 1.003 & 0.716 & 1.008 & 0.556 \\
\hline $\mathrm{FEV}_{1} / \mathrm{FVC}(\%)$ & 1.006 & 0.662 & 0.985 & 0.544 \\
\hline
\end{tabular}

Abbreviations: BMI, body mass index; $\mathrm{AHI}$, apnea hypopnea index; OSA, obstructive sleep apnea; $\mathrm{TS}_{90}$, percentage of time spent with an $\mathrm{SaO}_{2}$ below $90 \%$; mean $\mathrm{SaO}_{2}$, average pulse oxygen saturation; $\min \mathrm{SaO}_{2}$, lowest pulse oxygen saturation; ODI, oxygen desaturation index; FVC, forced vital capacity; $\mathrm{FEV}_{1}$, forced expiratory volume in the first second.
$47.7 \%, p=0.058)$, and, as the severity of OSA increased, the prevalence of hypertension increased $\left(\chi^{2}=4.483, p=0.034\right)$.

This study has several limitations. First, the study was cross-sectional, which precludes any conclusions regarding causality of the associations between OSA and polycythemia in OVS patients. Second, this study represents a preliminary study without further exploration of the underlying mechanisms that might explain the different effects of chronic sustained hypoxia and chronic intermittent hypoxia on erythropoiesis. Third, no long-term follow-up was available to study the impact of polycythemia on survival.

Regardless, considering the close association between polycythemia and OSA and its poor prognosis, PSG should be conducted in COPD patients with polycythemia in order to not miss the diagnosis and to initiate appropriate treatment.

\section{Conclusion}

Here, we found that patients with OVS had a higher prevalence of polycythemia than those with COPD alone and that $\mathrm{TS}_{90}$ is an independent factor for polycythemia, especially in GOLD1-2 COPD patients.

\section{Acknowledgments}

This study was supported by the National Natural Science Foundation of China (No. 81970082) and the National

Table 4 Results of Logistic Regression in Analyzing the Effect of OSA Severity and Other Parameters on Polycythemia According to GOLD Grade of COPD Patients

\begin{tabular}{|c|c|c|c|c|c|c|c|c|}
\hline \multirow[t]{3}{*}{ Parameters } & \multicolumn{4}{|c|}{ GOLD I-2 $(n=454)$} & \multicolumn{4}{|c|}{ GOLD 3-4 $(n=432)$} \\
\hline & \multicolumn{2}{|c|}{$\begin{array}{c}\text { Univariate Regression } \\
\text { Analysis }\end{array}$} & \multicolumn{2}{|c|}{$\begin{array}{c}\text { Multiple Regression } \\
\text { Analysis }\end{array}$} & \multicolumn{2}{|c|}{$\begin{array}{c}\text { Univariate Regression } \\
\text { Analysis }\end{array}$} & \multicolumn{2}{|c|}{$\begin{array}{c}\text { Multiple Regression } \\
\text { Analysis }\end{array}$} \\
\hline & OR & $p$ & OR & $p$ & OR & $p$ & OR & $p$ \\
\hline Age (year) & 0.937 & 0.005 & 0.955 & 0.081 & 0.908 & 0.005 & 0.891 & 0.006 \\
\hline BMI $\left(\mathrm{kg} / \mathrm{m}^{2}\right)$ & 1.162 & 0.001 & 1.040 & 0.567 & 0.995 & 0.947 & 1.046 & 0.683 \\
\hline Neck circumference $(\mathrm{cm})$ & 1.258 & $<0.001$ & 1.091 & 0.387 & 1.009 & 0.914 & 0.995 & 0.969 \\
\hline \multicolumn{9}{|l|}{$\mathrm{AHI}$ (events/h) } \\
\hline $\mathrm{AHI}<\mathrm{I5}$ & $\mathrm{I}$ & - & 1 & - & 1 & - & 1 & - \\
\hline $\mathrm{I} 5 \leq \mathrm{AHI}<30$ & 3.218 & 0.033 & 3.016 & 0.098 & 0.475 & 0.480 & 0.177 & 0.237 \\
\hline $\mathrm{AHI} \geq 30$ & 4.923 & 0.003 & 0.970 & 0.978 & 0.893 & 0.915 & 1.615 & 0.726 \\
\hline $\mathrm{TS}_{90}(\%)$ & 1.037 & $<0.001$ & 1.031 & 0.011 & 1.028 & $<0.001$ & 1.028 & 0.011 \\
\hline $\min \mathrm{SaO}_{2}(\%)$ & 0.948 & $<0.001$ & 0.978 & 0.353 & 0.872 & 0.133 & 0.990 & 0.751 \\
\hline mean $\mathrm{SaO}_{2}(\%)$ & 0.825 & 0.001 & 0.987 & 0.854 & 0.853 & 0.052 & 0.940 & 0.417 \\
\hline ODI (events/h) & 1.042 & $<0.001$ & 1.009 & 0.699 & 1.005 & 0.786 & 0.964 & 0.334 \\
\hline Tobacco use & 0.761 & 0.602 & 0.692 & 0.558 & 2.084 & 0.404 & 0.685 & 0.767 \\
\hline Alcohol use & 1.087 & 0.849 & 1.308 & 0.616 & 3.679 & 0.033 & 4.258 & 0.043 \\
\hline $\mathrm{FEV}, \%$ & 0.987 & 0.411 & 0.979 & 0.322 & 0.957 & 0.166 & 1.036 & 0.398 \\
\hline $\mathrm{FEV}_{\mathrm{I}} / \mathrm{FVC}(\%)$ & 1.020 & 0.472 & 0.996 & 0.918 & 0.954 & 0.113 & 0.943 & 0.185 \\
\hline
\end{tabular}

Abbreviations: $\mathrm{BMI}$, body mass index; $\mathrm{AHI}$, apnea hypopnea index; OSA, obstructive sleep apnea; $\mathrm{TS}_{90}$, percentage of time spent with an $\mathrm{SaO}_{2}$ below $90 \%$; mean $\mathrm{SaO}$, average pulse oxygen saturation; $\min \mathrm{SaO}_{2}$, lowest pulse oxygen saturation; $\mathrm{ODI}$, oxygen desaturation index; $\mathrm{FVC}$, forced vital capacity; $\mathrm{FEV}_{\mathrm{l}}$, forced expiratory volume in the first second. 
A

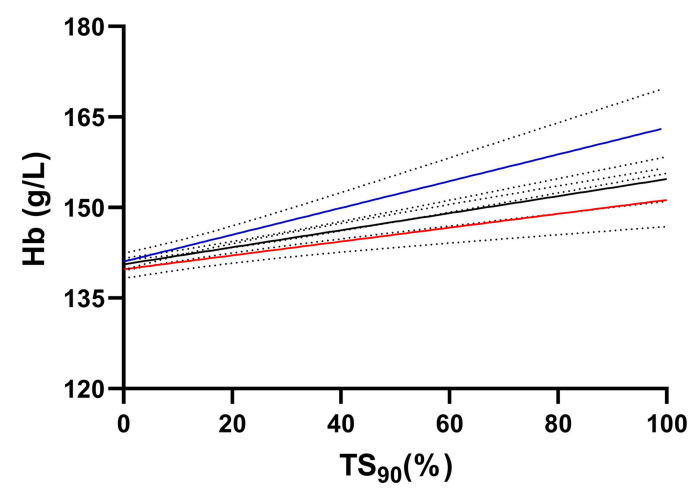

B

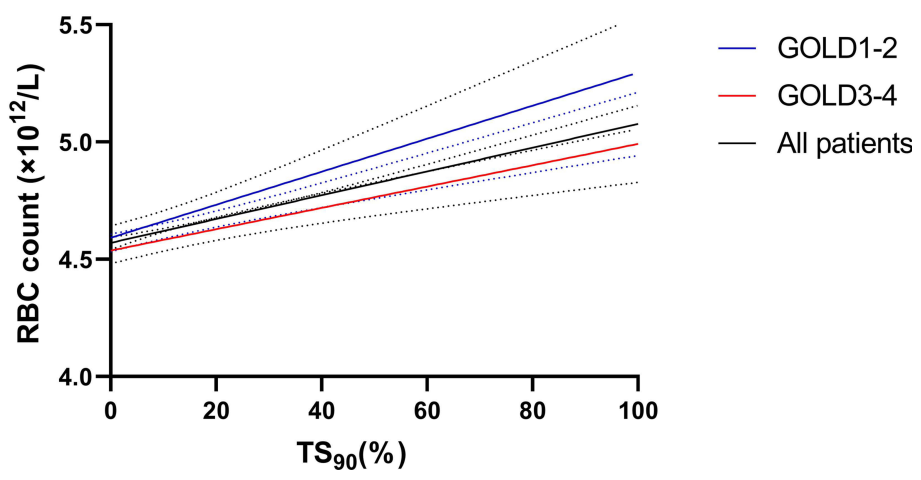

Figure 5 The effect of $\mathrm{TS}_{90}$ on RBC and $\mathrm{Hb}$ according to GOLD grade of COPD patients. Simple linear regression was applied to calculate trends and analysis of covariance was used to judge the significance of differences between linear regression slopes. (A) The difference in linear regression slope for Hb between GOLD I-2 and GOLD 3-4 patients $(F=5.799, p=0.016)$. (B) The difference in linear regression slope for RBC count between GOLD I-2 and GOLD 3-4 patients $(F=2.337, p=0.127)$.

Abbreviations: RBC, red blood cell; $\mathrm{Hb}$, hemoglobin.

Key Research and Development Program of China [Project Number: 2016YFC1304403].

\section{Disclosure}

The authors declare that they have no conflicts of interest.

\section{References}

1. D'cruz RF, Murphy PB, Kaltsakas G. Sleep disordered breathing and chronic obstructive pulmonary disease: a narrative review on classification, pathophysiology and clinical outcomes. J Thorac Dis. 2020;12 (S2):S202-16. doi:10.21037/jtd-cus-2020-006

2. Siegel FP, Petrides PE. Congenital and acquired polycythemias. Dtsch Arztebl Int. 2008;105(4):62-68. doi:10.3238/arztebl.2008.0062

3. Xu L, Chen Y, Xie Z, et al. High hemoglobin is associated with increased in-hospital death in patients with chronic obstructive pulmonary disease and chronic kidney disease: a retrospective multicenter population-based study. BMC Pulm Med. 2019;19(1):174-182. doi:10.1186/s12890-019-0933-4

4. Frank Y, Regev A, Novack V, et al. Incidence of hospitalizations among chronic obstructive pulmonary disease (COPD) patients with anemia. Harefuah. 2012;151(4):211-215. https://pubmed.ncbi.nlm.nih. gov/22616148/

5. Cote C, Zilberberg MD, Mody SH, et al. Haemoglobin level and its clinical impact in a cohort of patients with COPD. Eur Respir J. 2007;29(5):923-929. doi:10.1183/09031936.00137106

6. Boutou AK, Karrar S, Hopkinson NS, et al. Anemia and survival in chronic obstructive pulmonary disease: a dichotomous rather than a continuous predictor. Respiration. 2013;85(2):126-131. doi:10.1159/000338792

7. Fan $\mathrm{Z}, \mathrm{Lu} \mathrm{X}$, Long $\mathrm{H}$, et al. The association of hemocyte profile and obstructive sleep apnea. $J$ Clin Lab Anal. 2019;33(2):e22680. doi: $10.1002 /$ jcla. 22680

8. Gottlieb DJ, Punjabi NM. Diagnosis and management of obstructive sleep apnea: a review. JAMA. 2020;323(14):1389-1400. doi:10.1001/ jama.2020.3514

9. Nguyen CD, Holty JC. Does untreated obstructive sleep apnea cause secondary erythrocytosis? Respir Med. 2017;130:27-34. doi:10.1016/j. rmed.2017.07.003
10. Li N, Li HP, Wang P, et al. Nocturnal mean oxygen saturation is associated with secondary polycythemia in young adults with obstructive sleep apnea, especially in men. Nat Sci Sleep. 2019;11:377-386. doi:10.2147/NSS.S226143

11. Feliciano A, Linhas R, Marçôa R, et al. Hematological evaluation in males with obstructive sleep apnea before and after positive airway pressure. Rev Port Pneumol. 2017;23(2):71-78. doi:10.1016/j. rppnen.2016.12.001

12. Malhotra A, Schwartz AR, Schneider H, et al. Research priorities in pathophysiology for sleep-disordered breathing in patients with chronic obstructive pulmonary disease. An Official American Thoracic Society Research Statement. Am J Respir Crit Care Med. 2018;197(3):289-299. doi:10.1164/rccm.201712-2510ST

13. Ryan S, Taylor CT, Mcnicholas WT. Selective activation of inflammatory pathways by intermittent hypoxia in obstructive sleep apnea syndrome. Circulation. 2005;112(17):2660-2667. doi:10.1161/ CIRCULATIONAHA.105.556746

14. Kent BD, Mitchell PD, Mcnicholas WT. Hypoxemia in patients with COPD: cause, effects, and disease progression. Int J Chron Obstruct Pulmon Dis. 2011;6:199-208. doi:10.2147/COPD.S10611

15. Zhu J, Zhao Z, Nie Q, et al. Effect of lung function on the apnea-hypopnea index in patients with overlap syndrome: a multicenter cross-sectional study. Sleep Breath. 2020;24(3):1059-1066. doi:10.1007/s11325-01901961-w

16. Singh D, Agusti A, Anzueto A, et al. Global strategy for the diagnosis, management, and prevention of chronic obstructive lung disease: the GOLD science committee report 2019. Eur Respir J. 2019;53(5):164-176. doi:10.1183/13993003.00164-2019

17. Berry RB, Brooks R, Gamaldo C, et al. The American Academy of Sleep Medicine. In: Berry RB, Brooks R, Gamaldo CE, eds. The AASM manual for the scoring of sleep and associated events: rules, terminology and technical specifications 2.3 ed. Darien; 2016. Available from: URL: https://aasm.org/clinical-resources/scoringmanual/. Accessed January 08, 2021.

18. Frost A, Badesch D, Gibbs JSR, et al. Diagnosis of pulmonary hypertension. Eur Respir J. 2019;53(1):1801904. doi:10.1183/ 13993003.01904-2018

19. Mithoowani S, Laureano M, Crowther MA, et al. Investigation and management of erythrocytosis. CMAJ. 2020;192(32):913-918. doi:10.1503/cmaj.191587 
20. Zhang J, Demeo DL, Silverman EK, et al. Secondary polycythemia in chronic obstructive pulmonary disease: prevalence and risk factors. BMC Pulm Med. 2021;21(1):235-247. doi:10.1186/s12890-02101585-5

21. Pathak R, Giri S, Karmacharya P, et al. Obstructive sleep apnea syndrome and secondary polycythemia: analysis of the nationwide inpatient sample. Sleep Med. 2015;16(1):205-206. doi:10.1016/j. sleep.2014.09.012

22. Lundy SD, Parekh NV, Shoskes DA. Obstructive sleep apnea is associated with polycythemia in hypogonadal men on testosterone replacement therapy. J Sex Med. 2020;17(7):1297-1303. doi:10.1016/ j.jsxm.2020.03.006

23. Watts D, Gaete D, Rodriguez D, et al. Hypoxia pathway proteins are master regulators of erythropoiesis. Int $J$ Mol Sci. 2020;21 (21):8138-8156. doi:10.3390/ijms21218131

24. Song J, Sundar K, Gangaraju R, et al. Regulation of erythropoiesis after normoxic return from chronic sustained and intermittent hypoxia. J Appl Physiol. 2017;123(6):1671-1675. doi:10.1152/ japplphysiol.00119.2017

25. Krieger J, Sforza E, Barthelmebs M, et al. Overnight decrease in hematocrit after nasal CPAP treatment in patients with OSA. Chest. 1990;97(3):729-730. doi:10.1378/chest.97.3.729
26. Similowski T, Agustí A, Macnee W, et al. The potential impact of anaemia of chronic disease in COPD. Eur Respir J. 2006;27(2):390-396. doi:10.1183/09031936.06.00143704

27. Khan AM, Ashizawa S, Hlebowicz V, et al. Anemia of aging and obstructive sleep apnea. Sleep Breath. 2011;15(1):29-34. doi:10.1007/s11325-010-0326-7

28. Samareh Fekri M, Torabi M, Azizi Shoul S, et al. Prevalence and predictors associated with severe pulmonary hypertension in COPD. Am J Emerg Med. 2018;36(2):277-280. doi:10.1016/j. ajem.2017.08.014

29. Nakamura A, Kasamatsu N, Hashizume I, et al. Effects of hemoglobin on pulmonary arterial pressure and pulmonary vascular resistance in patients with chronic emphysema. Respiration. 2000;67 (5):502-506. doi:10.1159/000067463

30. Nadeem O, Gui J, Ornstein DL. Prevalence of venous thromboembolism in patients with secondary polycythemia. Clin Appl Thromb Hemost. 2013;19(4):363-366. doi:10.1177/1076029612460425

\section{Publish your work in this journal}

The International Journal of COPD is an international, peer-reviewed journal of therapeutics and pharmacology focusing on concise rapid reporting of clinical studies and reviews in COPD. Special focus is given to the pathophysiological processes underlying the disease, intervention programs, patient focused education, and self management protocols. This journal is indexed on PubMed Central, MedLine and CAS. The manuscript management system is completely online and includes a very quick and fair peer-review system, which is all easy to use. Visit http://www.dovepress.com/testimonials.php to read real quotes from published authors. 